\title{
Research in Building the Docking System of Higher Vocational Education and Social Needs
}

\author{
Wang Dong-ling \\ (Shandong Yingcai University,Jinan,Shandong,250104)
}

\begin{abstract}
As the cradle of personnel training, vocational schools have been widespread concerned for its' training objectives and personnel training quality. The key to deepening the reform of higher education institutions teaching profession is establishing the effective interface mechanism between the social needs and the personnel training quality of the vocational training institutions. Based on the DEA model, this paper builds an index system that includes input and output levels, and explains the meanings of these indexes detailedly, hoping this can play a reference in the actual operations of the Vocational Training Colleges.
\end{abstract}

KeyWords-Vocational education;Quality of personnel training;Index system;DEA model;

\section{INTRODUCTION}

The higher vocational education has been developing rapidly since the year 1999. Today there have 1215 higher vocational institutions and the colleges that are set up independently by the country. The number of the students has reached 965 million. All of these have made an irreplaceable contribution to our country 's popularization of higher education. With the development and improvement of the socialist market economy, more and more kinds of talented persons come into the labor market and go through the selection of market and appointment of society. As the cradle of personnel training, vocational schools have been widespread concerned for its' training objectives and personnel training quality. The key to deepening the reform of higher education institutions teaching profession is establishing the effective interface mechanism between the social needs and the personnel training quality of the vocational training institutions. Therefore how to establish the evaluation cohesion system of the a personnel training quality and social needs will become one of the key problems that need to be solved urgently. Based on previous studies, build a vocational education evaluation index system that are suitable for China's national conditions, complete and operational docking system of the personnel training quality and social needs. Thus contributing to the specific operations of vocational education.

\section{THE DESIGN PRINCIPLES OF INDEX SYSTEM}

We have already known that the cohesion system between the quality of the vocational education personnel training and social needs is a complex multi-input and multi-output system that consist of the source of talents, the selection of talents, the training of talents, the allocation of talents and continuing education and so on. The DEA method has unique advantages in evaluating the relative effectiveness between the multi inputs and multi outputs to the economical and social system. So it is suitable to apply the DEA methods evaluating the cohesion system between the quality of the vocational education personnel training and social needs.

To build the cohesion system evaluation index system between the quality of the vocational education personnel training and social needs, the input indexes are the series of investments, such as the selection, training, allocation, continuing education and administration of the talents. The output indexes are the training talents' all kinds of abilities.

The evaluation index must clearly identify the basis of the chosen index. In this paper, we choose the cohesion system evaluation indexes between the quality of the vocational education personnel training and social needs are based on the training model of personnel system. The cohesion system integrates the source and information, from the selection of the talents source, the selection, training of the talents to the continuing education and so on, which are included in the all processes of vocational education and social needs. On the basis of personnel training model, not only does the DEA can evaluate the efficiency of talent system, but also can evaluate the input and output results of personnel training on different aspects of the evaluation process. It also can evaluate the talents individual's abilities after having gone through the personnel training system.So in the process of designing the evaluation index system, the following principles should be obeyed:

a) Adequately and fully. The index system should cover the basic contents of personnel training fully, and have adequate representation.

b) Independent. Each index in the index system should be independent and has clearly meaning, and they can be build with separated group.

c) Operability. The data in the index system must can be obtained.

d) Comprehensive and systematic. The dynamic contact between each index should be closely, and each set of index can be integrated to form a complete index system.

e) Comparable. The relative index should be adapted as many as possible for the convenient of comparability of different kind of talents, years and so on.

QUALITY OF HIGHER VOCATION EDUCATION PERSONNEL TRAINING AND SOCIAL NEEDS COHESION EVALUATION INDEX SYSTEM DESIGNING

There is not a systematic and operable quality of higher vocation education personnel training and social needs cohesion evaluation index system in our country up to now. According to the above principles of designing an index 
system, in order to build an evaluation index system that is suitable to China's national conditions, the author discusses with relative experts about the practical problems of our country's higher vocational education personnel training, especially in some special cases, on the basis of analyzing plenty of relative articles at home and abroad.

\section{A. meaning and usage of each index}

input indexes

a. The proportion that the annual number of students who enter vocational schools accounts for its' planed enrollment should range from 0 to 1 . The indicator reflects the situation that how do vocational education schools control the source of talents in the practical implementation. The specific calculation method shown in the equation below:

$$
I_{1}=\frac{N_{y, k}}{N_{j m}} \times 100 \%
$$

$N_{y y k}$ _represent the total number of students who have their education in the vocational schools. $N_{j h}$---represent the total planed enrollment number of students of the vocational schools this year.

b. The average grades of people who passed the entrance examination should range from 0 to 100 . The indicator reflects the level of quality of the talents in the processes of personnel selection. The specific calculation method shown in the equation below:

$$
I_{2}=\frac{1}{n} \sum \text { Score }_{y i}, \quad i=1,2, \ldots, n
$$

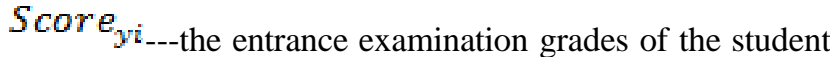
i.

n---the total number of students who pass the entrance examination.

c. The average grades of basic theory knowledge of students who enter the vocational education system should range from 0 to 100 . The indicator reflects the effect of the basic theory during the personnel training. The specific calculation method shown in the equation below:

$$
I_{3}=\frac{1}{N_{s}} \sum \frac{1}{N_{b k}} \sum \text { score }_{j / i}, i=1,2, \ldots, N_{s}
$$

Score $e_{j i}$ _the whole basic theory grades of the student $\mathrm{i}$ who entered the vocational education system that year.

$N_{s}$ - the total number of students that came into the vocational education system that year.

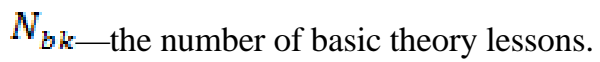

d. the average grades of vocational theory knowledge of students who come into the vocational education system should range from 0 to 100 . The indicator reflects the effect of the vocational theory during the personnel training. The specific calculation method shown in the equation below:

$$
I_{4}=\frac{1}{N_{s}} \sum \frac{1}{N_{/ t}} \sum \text { score }_{/ / i}, \quad i=1,2, \ldots, N_{s}
$$

scoresiz - the whole vocational theory grades of the student $\mathrm{i}$ who entered the vocational education system that year.

$N_{s}$ - the total number of students that came into the vocational education system that year.

$N_{l k}$ - the number of vocational theory lessons.

e. The average grades of vocational skills of students who came into the vocational education system should range from 0 to 100. The indicator reflects the effect of the training of vocational skills during the personnel training. The specific calculation method shown in the equation below $I_{s}=\frac{1}{N_{s}} \sum \frac{1}{N_{s k}} \sum$ score $_{I s i}, \quad i=1,2, \ldots, N_{s}$

Score $e_{\text {lsi }}$ - the whole vocational skills grades of the student $\mathrm{i}$ who entered the vocational education system that year.

$N_{s}$ - the total number of students that came into the vocational education system that year.

$N_{s k}$ - the number of vocational skills lessons.

f. The internship performance grades of the students who came into the vocational education that are comprehensively generated by the appraise of enterprises, clients and the guide teachers and so on should range from 0 to 100 . The indicator reflects the effect of training of practical skills during the personnel training. The specific calculation method shown in the equation below:

$$
I_{6}=\frac{1}{N_{t s}} \sum \frac{1}{N_{t}} \sum \text { Score }_{1 z i}, \quad i=1,2, \ldots, N_{s s}
$$

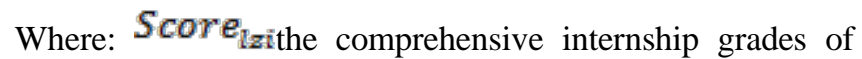
the student $\mathrm{i}$ who came into the vocational education system that are generated by all evaluation subjects.

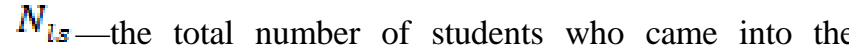
vocational education system having internship that year.

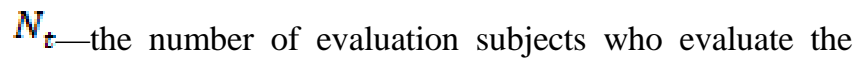
students who have their internship.

g. The proportion that the higher vocational education schools' infrastructure funding such as equipment, venue construction funding account for its total expenses should range from 0 to 1 . The indicator reflects the situation of infrastructure expenses during the personnel training. The specific calculation method shown as the following equation:

$$
I_{7}=\frac{\sum F_{m}}{\sum A_{n}} \times 100 \%
$$

Where: $F_{m}$-the m-th funding expenses of vocational education schools that are used in vocational education.

$A_{n-t}$ the total expenses of the n-th vocational education schools.

h. The proportion that the expenses of practical teaching account for the total expenses of various aspects of vocational education system should range from 0 to 1 . The indicator reflects the extent of emphasis that higher vocational education schools show to the training of 
vocational skills. The specific calculation method shown as the following equation:

$$
I_{\mathrm{s}}=\frac{\sum P_{k}}{\sum S_{/ /}} \times 100 \%
$$

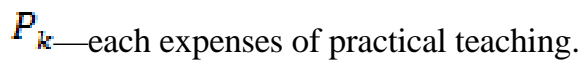

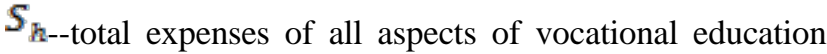
system.

i. The expenses that used in career information center of vocational education schools should range from 0 to 1 . The indicator reflects the extent of emphasis that vocational personnel system shows to the information and the examine of occupation personnel performance. The specific calculation method shown as the following equation:

$$
I_{9}=\frac{\sum V_{/}}{\sum S_{/ s}} \times 100 \%
$$

Where: $V_{i}$-the i-th expenses of vocational education schools' career information center.

$S_{h}$--the h-th aspect's total expenses of vocational education schools' career information center.

$\mathrm{j}$. The proportion that the number of people who had continuing education accounts for the number of vocational talents should range from 0 to 1 . The indicator reflects the extent of emphasis that occupation personnel system shows to the relearning ability of vocational talents. The specific calculation method shown as the following equation:

$$
I_{10}=\frac{N_{c e}}{N_{p z}} \times 100 \%
$$

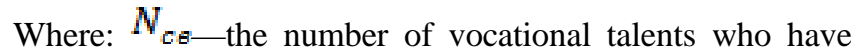
their continuing education that year.

$N_{p z}$

pz_-the number of vocational talents' allocation that year.

$k$. The proportion that the expenses used in the introduction of talents of those enterprises and institutions that need occupational skilled personnel accounts for the total expenses of those employers that year should range from 0 to 1 . The indictor reflects the extent of emphasis that employers show to talents during the allocation of occupational skilled personnel. The specific calculation method shown as the following equation:

$$
I_{11}=\frac{\sum H R_{\zeta}}{\sum \mathrm{F}_{\mathrm{j}}} \times 100 \%
$$

Where: $H R_{j}$-the expenses of introduction of vocational talents of the j-th employer.

$F_{j}$-the total expenses of the j-th employer that year.

\section{output indexes}

a. The proportion that the talents who engaged in theoretical jobs, such as teaching, accounted for the total number of the allocation of talents that year should range from 0 to 1 . The indicator reflects the theory level of the personnel training of vocational talents system. The specific calculation method shown as the following equation:

$$
O_{1}=\frac{\sum N_{l i}}{N_{p z}} \times 100 \%
$$

Where: $N_{l i}$ - the number of vocational talents who are engaged in the i-th theoretical jobs.

$N_{p z}$ _the total number of the allocation of vocational talents that year.

b. The proportion that the talents who were engaged in those practical skilled jobs accounted for the total number of the allocation of vocational talents should range from 0 to 1 . The indictor reflects the level of personnel training of vocational talents system. The specific calculation method shown as the following equation:

$$
O_{2}=\frac{N_{s s}}{N_{p z}} \times 100 \%
$$

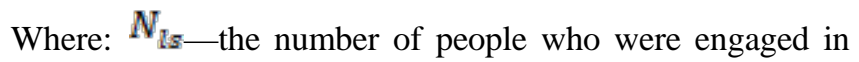
practical skilled jobs.

$N_{p z}$ _the total number of the allocation of vocational talents.

c. The proportion that the number of vocational talents who graduated from vocational education schools accounted for the number of vocational talents that the society needed should range from 0 to 1 . The indicator reflects the supply ability of vocational talents. The specific calculation method shown as the following equation:

$$
O_{3}=\frac{\sum P_{m}}{\sum P_{1}} \times 100 \%
$$

Where: $\sum P_{h x}$ - the number of vocational talents who graduated from vocational education schools that year.

$\sum P_{t P}$ - the number of vocational talents that the society needed that year.

$\mathrm{d}$. The proportion that the amount of missions which are completed with vocational skills accounted for the total amount of skilled missions that year. The indicator reflects the abilities that vocational talents apply their vocational skills. The specific calculation method shown as the following equation:

$$
O_{4}=\frac{\sum P_{z x}}{\sum P_{r}} \times 100 \%
$$

Where: $\sum P_{z y}$-the amount of missions completed with vocational skills that year.

$\sum P_{t}$ - the total amount of missions needed to be completed that year.

e. The proportion that the number of interns who are leaded by the workers accounted for the total number of interns at the same time should range from 0 to 1 that year. The indicator reflects the inheritance ability of the practical skills of vocational talents. The specific calculation method shown as the following equation:

$$
\mathrm{O}_{s}=\frac{\sum S_{d m}}{\sum S_{t}} \times 100 \%
$$




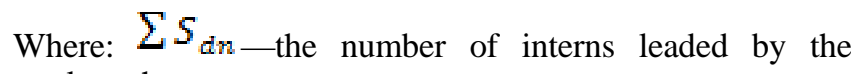
workers that year.

$\sum S_{t}$ - the total number of interns at the mean time.

f. The proportion that the vocational talents who took part in continuing education accounted for the total number of vocational talents at the mean time should range from 0 to 1 that year. The indictor reflects the relearning ability of the vocational talents. The specific calculation method shown as the following equation:

$$
O_{6}=\frac{\sum K_{d r}}{\sum K_{t r}} \times 100 \%
$$

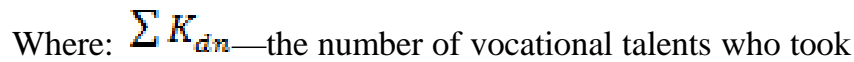
part in continuing education that year.

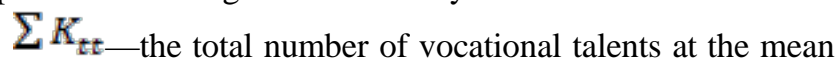
time.

These evaluation criteria from all sides reflect the docking extent that the quality of personnel training of higher vocational colleges and social needs, and can provide the basis for the scientific evaluation of training higher quality. It should be noted that: firstly, higher vocational colleges that are in different phase have different goals of personnel training, different extent in infrastructure expenses. And in internal administration or financial plans and so on, they also have enormously differences. So higher vocational education colleges must adjust the emphasis of evaluation according to its own features of different developing phase, take different consideration of the indexes' weight in the evaluation system. What's more, the docking system between the quality of personnel training of higher vocational education colleges and social needs is pretty complex. Interaction and interdependence are between these various factors, coupled with these guidelines are dynamic, changing and most of the guidelines are difficult to get a quantify description. So a fuzzy comprehensive evaluation that combines a qualitative assessment and a quantitative assessment should be taken in evaluating those guidelines.

\section{CONCLUSION}

Higher vocational education quality and social needs assessment docking in China started late, still no uniform assessment methods now. This paper aims at some beneficial discussing in the docking index system between the quality of personnel training of higher vocational education colleges and social needs. The essential difference between this paper to other papers is that we quantify the indicators. I hope this can play a reference in the actual operations of the Vocational Training Colleges.

\section{REFERENCE:}

[1] Wenting,Shi, Private colleges school risk and regulatory system construction,Exploring Education Development, vol. 24, PP. 44-48, 2008.

[2] Wang Xu, Private colleges risk management based on analytic hierarchy process, Exploring Education Development, vol. 3, PP. 26-31, 2013.

[3] Yueliang Zhou; Xiuqin Lin, "Mechanism of school organizational knowledge development," Natural Language Processing and Knowledge
Engineering, 2005. IEEE NLP-KE '05. Proceedings of 2005 IEEE International Conference on , vol., no., pp.818,824, 30 Oct.-1 Nov. 2005

[4] Yih-Ruey Juang; Tzu-Chien Liu; Tak-Wai Chan, "The Web-based performance support system for enhancing school based curriculum development," Advanced Learning Technologies, 2005. ICALT 2005. Fifth IEEE International Conference on , vol., no., pp.842,843, 5-8 July 2005

[5] Yuanhui Guan; Weihua Shi; Desheng Wu, "The Design and Development of a School File Management System for Standardized," Computer Science and Electronics Engineering (ICCSEE), 2012 International Conference on , vol.2, no., pp.630,634, 23-25 March 2012 